\title{
Skier triggering, snow temperatures and the stability index for dry-slab avalanche initiation
}

\author{
D. M. MCGLung, ${ }^{1}$ Jürg Sahweizer ${ }^{2}$ \\ ${ }^{1}$ Department of Geography, University of British Columbia, 1984 West Mall, Vancouver, British Columbia V6 1 1Z2, Canada \\ ${ }^{2}$ Swiss Federal Institute for Snow and Avalanche Research. Flüelastrasse 11, CH-7260 Davos, Switzerland
}

\begin{abstract}
For more than 30 years the quantitative method of evaluating stability (e.g. Roch, 1966; Föhn, 1987; Jamieson, 1995; Jamieson and Johnston, 1998a) has been focused on calculation of a strength-to-load ratio (or stability index): when the shear stress applied to the weak layer reaches the shear strength, failure is imminent. However, field observations combined with experience and measurements indicate that snow-slab temperatures and slab hardness can have a strong influence on dry-snow slab stability. In this paper, we present a simple static analysis of the stability index, and discuss the importance of slab temperatures and hardness and macroscopic size effects (factors not contained in the stability index) on snow-slab stability. Our conclusion is that the traditional method lacks some elements which are very important in snow-slab stability, particularly when skier triggering is involved.
\end{abstract}

\section{INTRODUCTION}

Most avalanches in western Europe and North America that result in deaths and injury occur during skiing (or snowmobiling or snowboarding), with people themselves serving as the triggering agent. Therefore, understanding the problem of skier triggering of dry-snow slabs is very important.

Instead of the traditional view that stability can be described by a strength-to-load ratio, McClung (1979, 1981, 1987, 1996) proposed an alternate view of dry-slab initiation: namely, that avalanche release depends crucially on both slab and weak layer, their interaction as a depcndent mechanical system and the mechanical properties of both. The result is that deformation (and the energy needed to form cracks) is the key to understanding avalanche release. Slab avalanches initiate by propagation of shear fractures in a weak layer under a slab and there are macroscopic sizc effects associated with such fracture initiation (Palmer and Rice, 1973; McClung, 1979, 1981, 1987, 1996; Bažant and Planas, 1998). Bažant and Planas (1998) show that when failures are described according to a strength or yield criterion alone (as with the traditional method), no such size effect is implied. The analysis in this paper includes for the first time a discussion of size effects in relation to skier triggering.

This paper is based on our experiences and ficld observations of snow temperatures and their effects on mechanical properties (including the slab) and skier triggering of avalanches. The influence of slab mechanical properties is overlooked in the traditional method of stability evaluation. As well as snow temperatures, we examine the stability index more generally with a simple stress analysis for skier loading on a snow slab. This analysis shows that if alpine snow is assumed to be a pressure-sensitive, Coulomb-Mohr matcrial (the traditional assumption), the stability index may either increase or decrease under static skier loading, which conflicts with experience. The discrepancy is cxplained by showing that the static stability index does not account for deformation and macroscopic impcrfections. We also emphasize the importance of dynamic effects for analysis of skier triggering by a comparison with the measurements of Schweizer and others $(1995 \mathrm{a}, \mathrm{b})$.

The fundamental argument in this paper is that macroscopic size effects and slab properties combined with dynamic effects are crucial in skier/human triggering, and that there are great variations in their combined effects. The result is to cast back-country avalanche forecasting as a risk analysis rather than a deterministic one based on an engineering stability index. We begin with a discussion of temperature effects on slab and failure properties in order to provide the link to slab properties, and conclude with a discussion of the stability index and size effects for skier triggcring.

\section{EFFECTS OF SNOW TEMPERATURE ON HARD- NESS, FAILURE TOUGHNESS AND STRENGTH}

The effects of snow temperature on hardness, failure toughness and shear strength have been described previously (McClung, 1995, 1996). Expericnce, field observations and measurements show that there are two important groups of competing effects: (1) metamorphism (depending on tempcrature, temperature gradient and other snow properties) and creep; (2) mechanical properties (excluding metamorphism effects), including snow hardness (initial tangent modulus in shcar which we tcrm stiffness), fracture propagation potential (fracture loughness which depends on stiffness) and strength. In this paper, we consider only the mechanical properties in group 2 for short time-scale changes in relation to skier triggcring. Crecp and metamorphism take more time to affect the temperature-dependent mechanical properties than the effects in group 2; the latter can be affected on timescales of scconds or less. 
Figure 1 shows a schematic of the effects and definitions of the terms based on our expcrimental results (McClung, 1996, and unpublishcd data from more than 200 tests by McGlung; Schweizer, 1998) from simple shear tests on alpine snow (for data description and expcrimental procedures see McClung, 1977; Schweizer, 1998). The shear strain rates range from $10^{3}$ to $10^{6} \mathrm{~s}$ and the tempcratures range from $-2^{\circ}$ to $-15^{\circ} \mathrm{C}$. The important effects sketched in Figure 1 from Schweizer (1998) are:

(1) Initial tangent modulus in shear is highly temperaturedependent. The increase in initial tangent modulus is $>100 \%$ as the temperature decreases from $-5^{\circ}$ to $-15^{\circ} \mathrm{C}$. This is the most important temperature-dependent property of alpine snow. In this paper, we use the tcrms initial tangent modulus in shear test, hardness and stiffness as synonymous. In engineering mechanics, hardness is usually related to tensile strength, but in practical work with the snow slab the relationship to resistance to shear deformation is much morc important. When the hand hardness test is used in field applications, people seek information about the relative relationship of shear properties of laycrs and the rclation to shear strength

(2) Failure strength (defined as peak on the stress-strain curve) can increase by $>20 \%$ as temperature dccreases over the range $-5^{\circ}$ to $-15^{\circ} \mathrm{C}$. Weak dependence of failure

\section{(a) GENERAL CONCEPT}

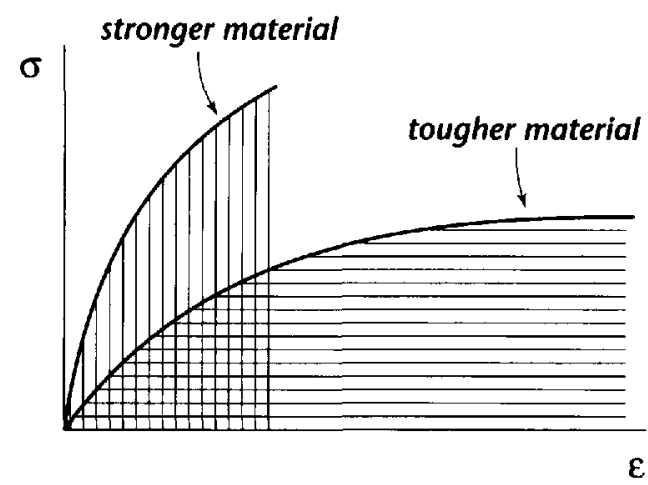

(b) ALPINE SNOW

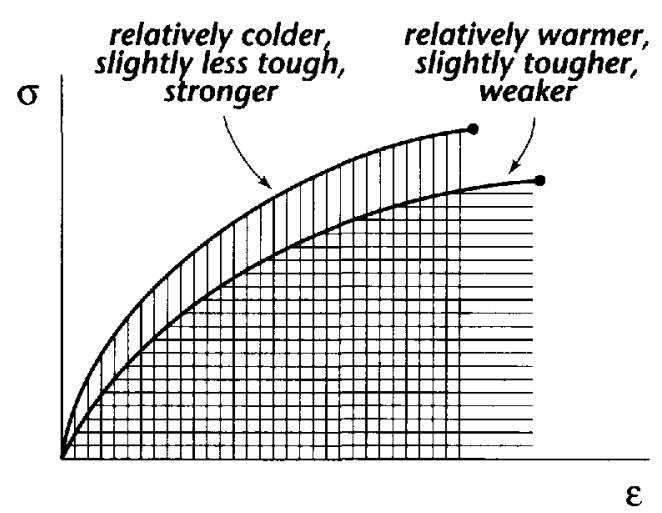

Fig. 1. Failure toughness and strength. (a) General concept with respect to stress ( $\sigma$ ) and strain ( $\varepsilon$ ). (b) Schematic for alpine snow in shear in relation to temperature and strength: toughness increases slightly with temperature increase whereas strength decreases. Figure $1 b$ is drawn mainly from data in Schweizer (1998). strength on temperature is a characteristic of most hightempcrature materials (Pisarenko, 1969). The conventional explanation of temperature effects on stability is based only on the decrease in strength with increasing tcmpcrature. Our measurements and theoretical arguments lead to the conclusion that strength decrease is not the major effect, particularly for skier triggering.

(3) Failure toughness (work input needed to reach a peak on the stress-strain curve) increases slightly with increasing temperature. It is equivalent to the area under the stress strain curve until a peak is reached. The failure toughness is related to the failure strain and failure strength. Data (Schweizer, 1998) show that failure strain decreases, resulting in a failure toughness which decreases as the tempcrature decreases by about $30 \%$ over the range $-5^{\circ}$ to $15^{\circ} \mathrm{C}$.

Results by Schwcizer (1998) indicate that when temperature and strain rate are studied together in a multivariate sense, temperature effects are more significant than ratc effects on initial tangent modulus. For peak strength and toughness, however, rate effects predominate over temperature effects. These results strengthen the argument that temperature cffects are most significant with respect to their effect on effective stiffness (or initial tangent modulus) (McClung, 1996).

Since the hardness (or initial shear modulus) is strongly tempcrature-dependent, it is likely that fracture toughness for the snow-slab problem increases as temperature decreases, since fracture toughness is proportional to the square root of the shear modulus (e.g. McClung, 1996). Since peak strength increases as temperature decreases, and failure displacement decreases as temperaturc decreases, it is likely that the shear modulus controls the temperature dependence of fracture toughness. This expectation matches that for other high-temperature materials. Broek (1986) argues that alloy steels and other materials show an increase in fracture toughness as the temperature decreases similar to what we expect for alpine snow.

Field data (Perla, 1977; sce also McClung and Schacrer, 1993) show that avalanche frequency is less when weak-layer failure temperatures are cold. We believe the decrease in frequency could bc duc in part to an increase in slab stiffness with decreasing temperature, because colder weak layers also imply colder slab temperatures. However, there are other complicating factors which prevent a direct correlation (McClung, 1996)

\section{SKIER TRIGGERING AND SNOW TEMPERATURES}

Consider now the casc of skicr triggering with the immediate effects of snow temperatures on stiffness and failure toughness. When a skier moves over a snowpack a dynamic load is applied to the snow cover and the stresses penetrate through the entire depth of the snow cover (sce, e.g., Föhn, 1987, for a static analysis). In order to generate propagating shear fractures in a weak layer, a skier will have to impart significant deformation energy to the layer. While crack initiation will depend on stresses, the formation and propagation of cracks requires deformation cncrgy (Bažant and Planas, 1998). It is not possible to generate propagating fracturcs, cven if stresses are very high, unless the required deformation energy is applied. Mcasurements of snow deformation imparted by skis (Schweizer and others, 
1995a, b) show that the most important variable with respect to the penetration of significant deformation is the snow hardncss. Harder layers permit less deformation at depth than softer layers, thereby reducing the chance of failure. Furthermore, by the argument above, snow hardness increases rapidly with decreasing temperature.

Combining the above results, increasing snow temperatures can rapidly decrease snow-slab stability in two ways. (1) By decreasing the delaycd clastic (or viscoelastic) stiffness of surface (slab) layers, significant deformation may penctrate decper in the snow cover to increase weak-layer deformation and allow easier failure (more deformation) and propagation. (See McClung (1996) for a discussion of delayed elasticity and its relation to temperature dependence. The analysis shows that slab temperature effects reside in delayed elastic (viscoelastic) response rather than the time-independent elastic modulus.) (2) If warming temperatures also reach the weak layer, failure toughness is increased slightly (Schwcizcr, 1998), but peak strength is reduced to produce only small changes in the ease with which failure takes place. Of these two processes, we consider the first to be the more important, from our extensive failure data on snow.

$\Lambda$ person on skis is directly in contact with the surface layers, and deformation energy to the weak layer must be communicated through the slab. Furthermore, surface layers are subject to great variations in temperature, and snow hardness is affected rapidly. Therefore, one can expect the stability to vary greatly when conditions are right, depending on the hardness of the surface layers and their fluctuating temperatures. For example, on a cold morning or northerly aspect (Northern Hemisphere) when surface layers are cold and hard, deformation under skis will not penetrate as far and as effectively as later on or at other places where surface layers are warmer. Furthermore, the effect on stability can be rapid when surface layers warm: metamorphism or significant creep (settlement) effects are not required since the viscoelastic (delayed elastic) properties are affected almost immediately on loading. Figure 2 shows a schematic of the expected snowpack deformation patterns for a person on skis. Further information on skier deformation is provided in the Appendix.

\section{STABILITY TESTS}

\section{(1) Rutschblock test}

The suggestions above have important implications for interpretations of common stability tests used by skiers, particularly the Rutschblock test. (See McClung and Schaerer (1993) for descriptions of the common stability tests.) The interpretation of the Rutschblock test is complicated since the results are highly dependent on the hardness of the surface layers. Since hardness of surfacc laycrs can vary considerably, not only spatially across a slope but also rapidly in the vertical directions with time as layer temperatures change, it may be expected that Rutschblock test results can vary significantly with snow-slab temperatures. At a location, it is possible to go from a condition indicating stability to one of instability as surface layers warm to allow decper penctration of deformation energy. Therefore, the Rutschblock may sometimes only test the surface layer hardness and its propensity for deformation penetration rather than indicatc instability at a location. The Rutschblock test

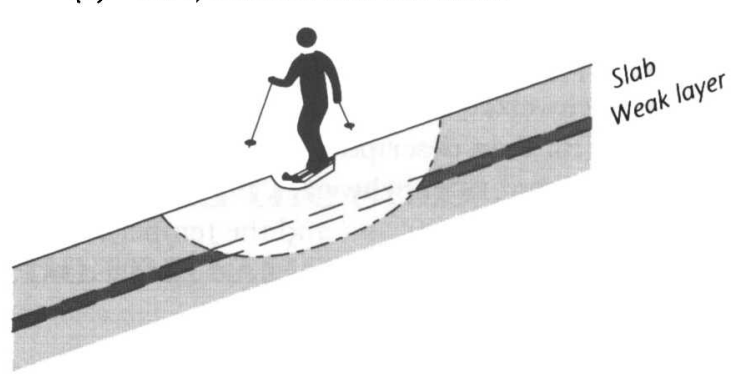

(b) HARD, COLDER SURFACE LAYER

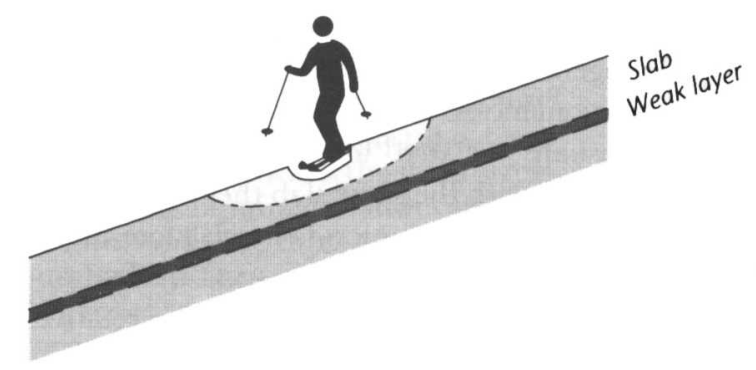

Fïg. 2. Schematic of deformation patterns for a skier.

measures primarily surface layer deformation, but if deformation penctrates decp cnough with enough deformation energy to fail snow in a weak layer it indicates local instability. A great advantage of the test is that it includes provision for application of dynamic loads which can partially replicatc skicr loading. 'Ihus, interpretation of the Rutschblock is not simple, and results may vary according to hardness variations of the surface layers (Jamieson and Johnston, 1995). Such highly variable results have been amply demonstrated (Föhn, 1989). At a given location, the Rutschblock is a very good test, but extrapolation to other locations is complex if surfacc hardncss conditions change, for example due to temperature or wind-packing variations.

\section{(2) Shovel shear test}

The shovel shear test also has limitations McClung and Schacrer, 1993) but it is simpler to interpret than the Rutschblock test, and variations in test results are duc primarily to strength variations in the layer tested rather than a combination of surfacc hardness changes and weak-layer strength variations as in the Rutschblock test. Once the weak layer is found, the shovel shear test gives a qualitative estimate of weak-layer strength (based on the applied force necessary to reveal a shear failure), as well as an indication of the quality of any shear-failure planc formed.

\section{(3) Shear frame test}

The shear frame test is similar to the shovel shear test in that it tests true variations in weak-layer strength. It gives a more quantitative index of weak-layer strength. As with the shovel shcar test, the wcak layer has to be found first. The method involves special techniques appropriate for special investigations and professional services. It is useful to follow the evolution of weak-layer strength in a relative sense, and combincd with experience it can also be used to assess stability. Potential limitations of this method have been studied by Perla (1980), Föhn (1987) and Jamieson (1995).

Ficld cxpcricnce shows that near-surface layer proper- 
ties are very important for skier triggering, and the results of Schweizer and others (1995a, b) confirm that deformation and stresses are sensitive to surface layer properties. For example, field practitioners apply the term "bridging" when slab material is hard (or stiff) and deformation energy at depth is reduced to lessen the chance of avalanche initiation by a skier. Our work provides experimental and theoretical evaluation of this important effect which practitioners have developed from experience. In order to be effective, stability tests must be supplanted with information about slab mechanical properties.

\section{STABILITY INDEX AND SKIER TRIGGERING}

The stability index (also called a strength-to-load ratio) is normally defined as the ratio of shear strength in the weak laycr to applicd shcar stress for describing the possibility of slab-avalanche initiation. The shear strength is normally defined by an index of weak-layer strength using the shear frame. The shear stress is defined from density measurements in the slab as the downslope component of body force per unit area applied to the weak layer. In practice, stability-index calculations are sometimes performed in places such as level study plots, and instead of shear stress in the calculations the summed product of density and snow depth is used for the load. Perla (1980) reviewed the difficulties and problems with the use of the shear frame, but he concluded, and it is still true, that there is nothing better to replace it for quantitative field estimates. Besides a multitude of disadvantages with the shear frame there are two additional drawbacks of the stability index for use on the skier-triggering problem: (1) the stability index does not include important slab properties such as hardness and the effects of snow temperatures on slab hardness; (2) measurements of shear strength using the shear frame do not encompass information about the effects of imperfections and macroscopic size effects, whereas such information likely plays a crucial role in avalanche initiation under skier triggering. Other common stability tests do not contain such information either. Below, we illustrate (mathematically) properties of the stability index (ratio) to further clarify its role in evaluating snow-slab stability and describing skier triggering with emphasis on size effects.

\section{STABILITY-INDEX STRESS ANALYSIS}

In this section, we investigate the properties of the stability index mathematically under two types of applied loading increments: loading increments from ncw snowfall and from a skier approximated as a line-source load (Föhn, 1987). Figure 3 is a schematic of the geometry and applied load. Following the conventional approach (Perla, 1980; Föhn, 1987; Jamieson and Johnston, 1998a), we approximate the shear strength, $\tau_{\mathrm{s}}$, most simply as a linear, pressurc-dependent (frictional) Coulomb Mohr material with strength components: cohesion $(C)$ and friction expressed as the product of a friction coefficient, $\mu$, and applied normal stress, $\sigma$, with both $\mu$ and $C$ taken constant:

$$
\tau_{\mathrm{s}}=C+\mu \sigma .
$$

In order to simplify the notation, we write $\sigma=\sigma_{x x}(H)$, the mean normal stress applied to the weak layer (in Cartesian coordinates) for a planar slab of depth $H$; and similarly $\tau=\tau_{x y}(H)$ is the mean shear stress. From Equation (1), the

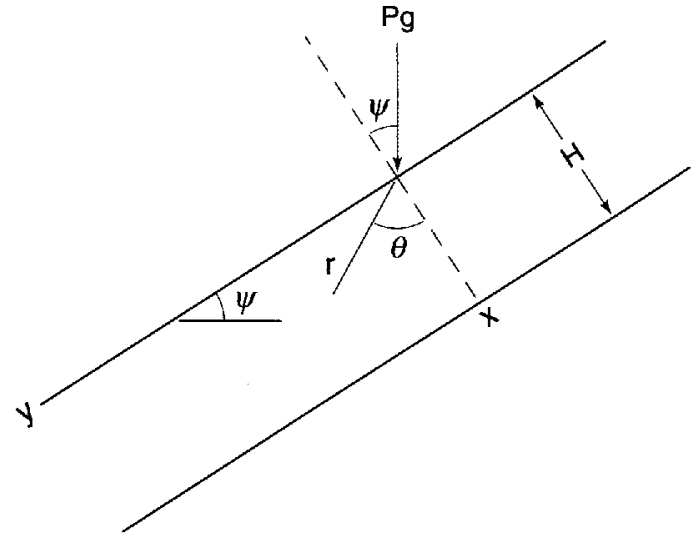

Fig. 3. Geometry for line-source loading of a skier where $P$ is load ( $\mathrm{kg}$ ) per unil length.

stability index, $S_{0}$, prior to new snow load or skier loading is given by:

$$
S_{0}=\tau_{\mathrm{s}} / \tau
$$

\section{NEW SNOWFALL LOADING}

Consider now the additional loading by snowfall with mean density $p$, slope angle $\Psi$ and incremental depth $\Delta H$; then the incremental shear and normal load added are:

$$
\begin{aligned}
& \Delta \tau=\rho g \sin \Psi \Delta H \\
& \Delta \sigma=\rho g \cos \Psi \Delta H .
\end{aligned}
$$

The new stability index, $S^{\prime \prime}$, then becomes:

$$
S^{\prime \prime}=\frac{C+\mu(\sigma+\Delta \sigma)}{\tau+(\tan \Psi) \Delta \sigma}
$$

From Equation (4), the stability index increases under loading if

$$
\frac{\mathrm{d} S^{\prime}}{\mathrm{d} \Delta \sigma}>0
$$

and the stability index decreases under loading if

$$
\frac{\mathrm{d} S^{\prime}}{\mathrm{d} \Delta \sigma}<0
$$

From Equation (4) these conditions are (under snowfall loading):

$$
\begin{aligned}
& \mu>(\tan \Psi) S_{0}: \text { stability increases } \\
& \mu=(\tan \Psi) S_{0}: \text { stability unchanged } \\
& \mu<(\tan \Psi) S_{0}: \text { stability decreases }
\end{aligned}
$$

However, given the definition of $S_{0}$ from Equation (2), it is easily shown that the stability always decreases when the cohesion $C$ is greater than zero: a condition we take to be always fulfilled by alpine snow in buried weak layers. Mathematically, therefore, stability is implied to decrease for new snowfall loading assuming Equation (1). However, data for $\mu$ and $S_{0}$ might imply otherwise as we show below.

Consider typical values for the parameters in Expressions (3) from the perspective of data. Perla (1977) analyzed data from 23 avalanche fracture lines combined with shear frame measurements and obtained a mean value of $S_{0}=$ 1.66. Föhn (1987) obtained an average value of 2.3 for 18 natural slabs. Jamieson (1995) determined higher values during natural avalanche release with the values taken from a study plot instead of at fracturc lines, with most avalanche occurrences when $S_{0}$ was $<3$. 
We take the effective friction cocfficient $\mu=\tan \phi$ (where $\phi$ is peak friction angle for the material at the weak layer). Measurements for homogeneous samples by McClung (1987) give friction angles in the range $40-70^{\circ}$ for direct simple shear: the expected strain and stress conditions prevailing in a thin, homogeneous weak layer. Roch's (1966) static friction angles varied from $37^{\circ}$ to values exceeding $60^{\circ}$. Taking the simple shear values for $\mu=0.75-2.75$ for the left side of Expressions (5), in comparison with $\Psi=35^{\circ}$, the right side has the value 1.16 for Perla's (1977) average. We conclude that, from the perspective of data, any of the conditions of Expressions (5) might be fulfilled. This seems contradictory and we believe the explanation lies with the values of the friction angles. If we use Jamieson's (1995, p. 38) values for $S_{0,}$, stability would be implied to increase with loading.

The same problem occurs in explaining landslide releases (Bjerrum, 1967): peak friction angles from smallsample-size testing machines are routinely higher than slope angles measured for the landslide occurrences. Our analysis above extends Bjerrum's constant-load observation to that for new snowfall loading. The contradiction for the landslide problem was a major factor which led Palmer and Rice (1973) to introduce strain-softening properties and size effects into the landslide literature, and McClung (1979, 1981) proceeded by analogy to apply similar theory for snow-slab failure. Our analysis provides further evidence that the shear frame provides an index property but does not account for macroscopic sizc cffects. Bclow we provide an analysis of macroscopic size effects on fracture initiation to emphasize this point.

If friction angles are derived from shear frame measurements for very weak, anisotropic layers, different conclusions result. According to Jamieson and Johnston (1998a), shear frame measurements show some persistent snow layers (c.g. surface hoar) to be ncarly pressurc-insensitive, and therefore $\mu \approx 0$ and from Expressions (5) new snow loading (or skier loading as shown below) always increases instability. We believe there is high uncertainty about the true values of friction angles for such layers and the analysis applying them. The shear frame has large stress concentrations around the fins that act as cross-members (e.g. Jamieson, 1995) to divide the frame. It seems likely that crystals like surface hoar or facets may display preferential deformation when sheared rapidly in the presence of stress concentrations. If the shear frame forces preferential deformation in shear near the fins, an underestimate of pressure sensitivity can result. Therefore, the imprecision in stress and strain conditions for shear frame might limit its usefulness in studying the effects of normal stresses on shcar strength. Mcasurements (McClung, 1987) with the Norwegian Geotechnical Institute simple shear apparatus (with much better stress and strain conditions) consistently show higher friction angles than those estimated from shear frames, and such measurements include faceted snow which is an important avalanche-failure layer.

\section{STATIC SKIER LOADING}

In this section, we investigate the properties of the stability index for skier loading similar to Föhn's (1987) analysis (the original treatment of this problem is due to Boussinesq in 1892). Föhn (1987) considered the stresses for this problem but did not include an analysis of the stability index. Jamieson and Johnston (1998a) considered refinements to the static stability index, but neither Föhn nor Jamieson and Johnston considered the mathematical analysis we present here. We neglect inertial effects and macroscopic weak-layer imperfections and approximate the load a skier applies to a snowpack as a line source over an clastic half-space. Even though our analysis is static, as a first approximation the dynamic problem might be examined by studying steady-state response to a moving line load at constant speed over an clastic half-space, but this is beyond the scope of the present paper. From Figure 3, we consider the load to be applied in the direction toward the centre of the Earth with magnitude $P\left(\mathrm{~kg} \mathrm{~m}^{-1}\right)$. It is convenicnt to write the applicd stress in polar coordinates $(r, \theta)$ since then the only stress is in the radial direction (Timoshenko and Goodier, 1970):

$$
\Delta \sigma_{\mathrm{r}}=\frac{2 P g(\cos \Psi \cos \theta+\sin \Psi \sin \theta)}{\pi r} .
$$

From Equation (6), we may writc:

$$
\begin{aligned}
& \Delta \sigma=\Delta \sigma_{\mathrm{r}} \cos ^{2} \theta \\
& \Delta \tau=\Delta \sigma_{\mathrm{r}} \sin \theta \cos \theta .
\end{aligned}
$$

From Equation (7), the loading ratio is:

$$
\frac{\Delta \tau}{\Delta \sigma}=\tan \theta
$$

From Equation (8), repeating the analysis leading to Expressions (5) gives:

$$
\begin{aligned}
& \mu>\tan \theta S_{0}: \text { stability increased } \\
& \mu=\tan \theta S_{0}: \text { stability unchanged } \\
& \mu<\tan \theta S_{0}: \text { stability decreased }
\end{aligned}
$$

For typical parameters, the last condition is fulfilled if $C>0$ and $\Psi<\theta$ : stability always decreases under skier loading. However, as with Expressions (5), we show below that this condition may appear to be violated if $S_{0}$ is evaluated from shear frame measurements combined with information known about peak friction angles to imply that stability increases under skier loading.

For a wcak layer at a given depth, $H$, in polar coordinates, the depth may be expressed as $H=r(H) \cos \theta$. The cxpression for the perturbation shear stress load is:

$$
\Delta \tau(H)=\frac{2 P g \cos (\Psi-\theta) \sin \theta \cos ^{2} \theta}{\pi H} .
$$

From Equation (10), the angle $\theta$ at which the maximum shear stress loading is about $35^{\circ}$ for $\Psi$ is in the range $25-45^{\circ}$ (the range of most slab-avalanche slope failure angles). Therefore, it may be justifiable to simplify Expressions (9) by approximating $\tan \theta \approx 0.7$. From Perla's (1977) average $\left(S_{0}=\right.$ 1.66) and from Expressions (9) it is implicd that stability is increased by skier loading if $\mu=\tan \phi>1.16$ or for friction angles of $>49^{\circ}$. Such a condition is often fulfilled if measurements of homogencous, isotropic snow are used (40$70^{\circ}$ ) from the data of Roch (1966) or McClung (1987). Since Perla's data are from natural releases, the mean value of $S_{0}$ may be higher for actual skier triggering, which reinforces the prediction of increased stability.

The number of accidents associated with skier triggering (e.g. Jamieson and Geldsetzer, 1996) shows that skiing has a negative influence on stability. We believe that the static analysis above neglects two important effects: (1) the dynamic effects in skiing (see Appendix and the results of Schweizer and others, 1995a, b) are neglected, and (2) the 
measurements (shear frame or simple shear) do not take into account that macroscopic imperfections in weak layers and at their boundaries are the most likely genesis of avalanche formation. Most shear frame analyses yicld results for $S_{0}>1$ when the snow pack can be highly unstable (e.g. Perla, 1977). Clcarly, if shcar frame measurements containcd the important information about imperfections, the measurements would show $S_{0} \leq 1$ when there is instability in the snow cover. Perla's (1977) fracture-line data are easily explainable from the view that the initial fracturcs propagated from weak fracture zones underneath the snow slabs with termination in stronger snow at the fracture lines.

Many attempts have been made to explain the discrepancy between the strength-to-load ratio $\left(S_{0}>1\right)$ and observed instability by attributing size effects in a statistical sense to the shear frame using Weibull or Daniels statistics of micro-scale flaws (e.g. Sommerfeld, 1980; Fŏhn, 1987; Jamieson and Johnston, 1998a ). Bažant and Planas (1998; sce also Freudenthal, 1968, p. 615) present a comprehensive summary of size effects for quasi-brittle (strain-softening) materials, and conclude that Weibull statistics are not applicable to this class of materials for explaining size effects of large-scale failures such as the snow slab. They show that statistical approaches such as the Weibull theory apply only to failures in which the material just before failure contains only microscopic cracks or other flaws such as for brittle materials. Materials which fail after macroscopic imperfection growth (the quasi-brittle or strain-softening materials) are governed by such macroscopic effects, and the emphasis is on stress redistributions which mitigate the cffect of microscopic flaws.

The alternate view is that micro-scale statistical aspects of fracture (e.g. Daniels (or the bundle model) or Weibull statistics as discussed by Sommerfeld (1980) ) can be used to reduce the strength measurements from shear frames to yield $S_{0}$ values that are $\leq 1$ for most avalanche events (including skier triggering). With respect to application of a bundle model, Freudenthal $(1968$, p. 609) states that such a model applies only to a description of fracture processes in materials for which bundles such as long-chain molecular filaments physically exist such as linear high polymers or elastomers which fail after chain orientation after large strain. We believe there are size effects associated with the shear frame, and, as such, the shear frame is only an index, but the size effects in avalanche fractures are macroscopic not micro-scale in size.

\section{STATIC STRESS ANALYSIS OF SKIER LOADING}

It is interesting to compare the approximatc load generated by a skier (Equation (10) with the value of $\tau$ from the weight of the slab. From Equation (10), the non-dimensional ratio is:

$$
\frac{\Delta \tau(H)}{\tau}=\frac{2 P}{\pi \rho_{s} H^{2}} \frac{\cos (\Psi-\theta) \sin \theta \cos ^{2} \theta}{\sin \Psi} .
$$

For a skier of mass $70 \mathrm{~kg}$, and length of ski $1.70 \mathrm{~m}$, the value of $P$ in the above equation representing the linc sourcc is $P=$ $70 /(1.70)=41.2 \mathrm{~kg} \mathrm{~m}^{-1}$. For typical values $\theta=35^{\circ}, \Psi=35^{\circ}$ and average slab density $\rho_{\mathrm{s}}=200 \mathrm{~kg} \mathrm{~m}^{-3}$, the ratio above is given by $0.088 / H^{2}$ and it ranges from 0.35 at $H=0.5 \mathrm{~m}$ to 0.09 at $H=1.0 \mathrm{~m}$ and 0.02 at $H=2.0 \mathrm{~m}$, as shown in Figure 4 .

Application of values for cohesion of surface hoar (values range from 1.5 to $3.5 \mathrm{kPa}$ corrcctcd for statistical size

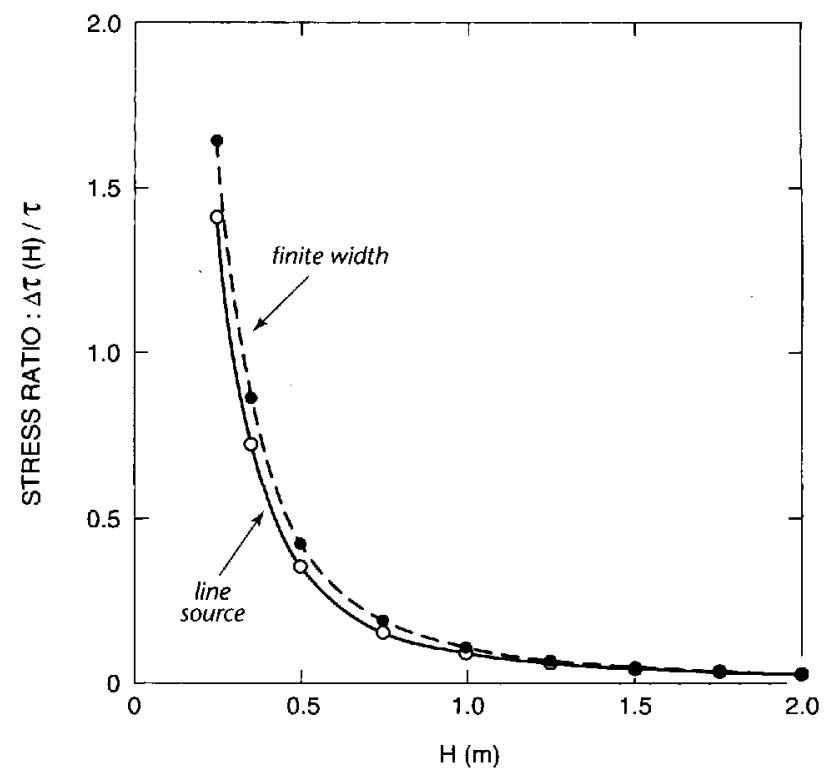

Fig. 4. Stress ratio as a function of depth for a skier approximated as a line-source loading. Alsa shown is a comparison for a skiof widh $0.1 \mathrm{~m}$ ( see Appendix). The geometry is shown in Figure 6.

effects) by Jamieson and Johnston (1998a) with $\mu$ assumed to be zcro, as they recommend, shows that the unperturbed stability index given by Equation (2) predicts stability $\left\langle S_{0}>1\right.$ ) for snow depths greater than $1.24 \mathrm{~m}$ (cohesion $1.5 \mathrm{kPa}$ ) and $2.90 \mathrm{~m}$ (cohesion $3.5 \mathrm{kPa}$ ). When the stability index includes static skier loading as calculated in Figure 4 these values are reduced to 1.18 and $2.86 \mathrm{~m}$, nearly negligible differences.

The actual stress values compared with typical strength valucs are also of intercst. With the above values, Equation (10) gives $\Delta \tau=99 / H$ (Pa) where $H$ is in meters (see Fig. 5). If $H=1 \mathrm{~m}$ then the stress added is about $100 \mathrm{~Pa} 200 \mathrm{~Pa}$ for $0.5 \mathrm{~m}$ ) which, from field measurements, is close to the minimum for shear strength estimated from fracture lines for failure density $100 \mathrm{~kg} \mathrm{~m}^{3}$ (see McClung and Schacrer, 1993, p. 71). Virtually all of Jamieson's (1995) strength esti-

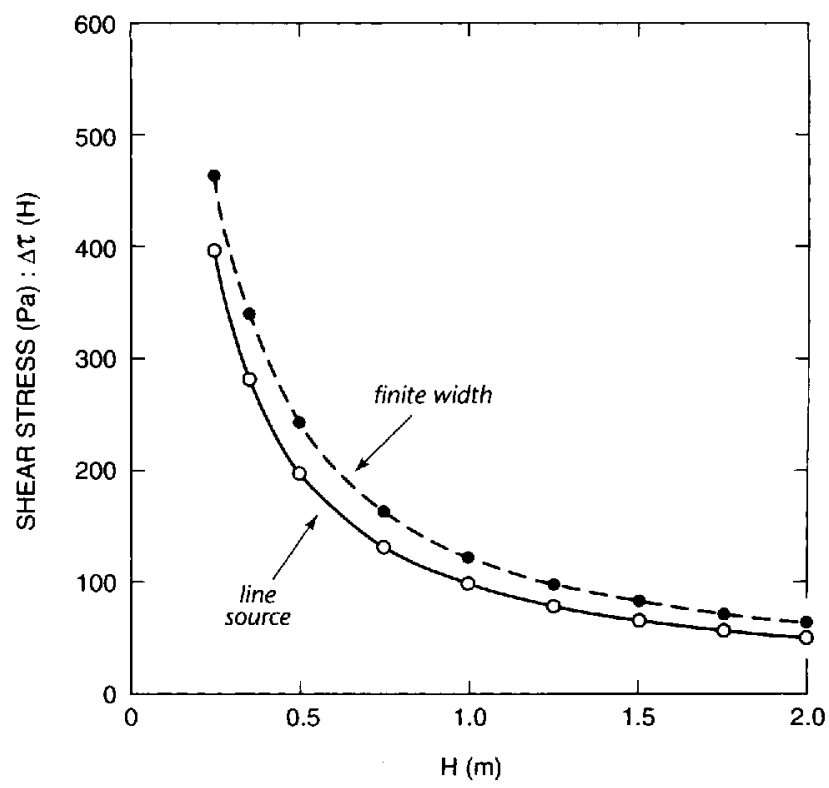

Fig. 5. Shear stress as a function of depth for a skier approximated as a line-source loading. Also shown is a comparison for a ski of width $0.1 \mathrm{~m}$ (see Appendix). The geometry is shown in Figure 6. 
mates exceed these values by more than a factor of 3 . The conclusion is that skicr loading by such analysis (excluding imperfections and dynamic effects) is nearly insignificant below $1 \mathrm{~m}$ depth.

Even though the analysis shows nearly ncgligible stresses in comparison with slab values below about $1 \mathrm{~m}$ in the snowpack, it is known that skiers can rarely trigger avalanches as decp as $1 \mathrm{~m}$ (see Jamicson and Johnston, 1998b, for data). Jamieson and Geldsetzer (1996) showed that about $11 \%$ (sample of 261) of recreational accidents (including snowmobile accidents) in Canada during 198496 involved averagc slab thicknesses of $>1 \mathrm{~m}$. Jamicson and Johnston (1998b) compiled start-zone data on 1193 skier-triggered avalanches observed by helicopter skiing guides. These data showed that depth excecded $40 \mathrm{~cm}$ in $25 \%$ of cases and $65 \mathrm{~cm}$ in $10 \%$ of cases, but maximum depth was $2 \mathrm{~m}$. There is uncertainty in such data because all are related to fracture lines, not the actual position where fracture initiated. Ficld observations (personal communication from D. Fesler, 1998) often show that fractures propagate into deeper areas following skier triggering, so that fracture-line depths are often greater than slab depths at the initiation triggering point.

\section{STATIC ANALYSIS WITH EFFEGT OF FINITE SKI WIDTH}

The analysis above is for a line-source loading of infinitesimal width. Föhn (1987) considered a similar analysis to approximate snowcat loading, but he did not consider a ski of finite width. In the Appendix, we give an analysis for which skier loading is approximated near the centre of a ski of finitc width on a slope as a plane-strain analysis. Figure 6 shows the loading situation. In order to compare with the line-source analysis above, we calculated the stress distribution for the same parameters as in Figures 4 and 5: $\Psi=$ $35^{\circ}, \theta=35^{\circ}$, for a ski of width $10 \mathrm{~cm}$. Figures 4 and 5 show these calculations in comparison to calculations for the line source. The results show very little difference between this and our previous analysis.

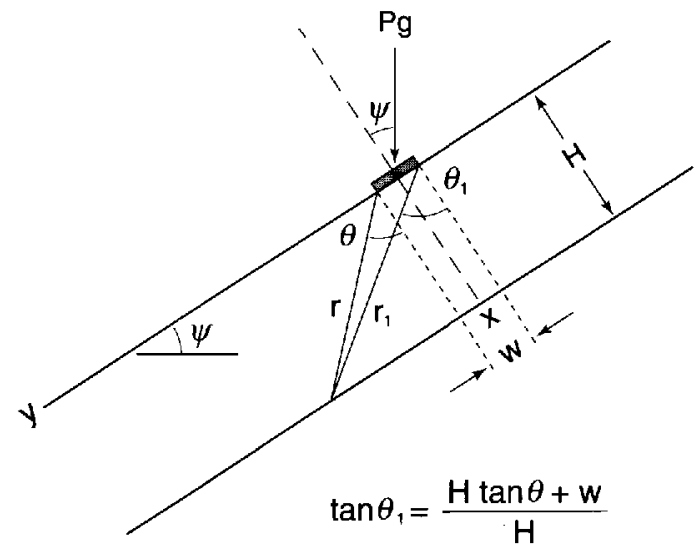

Fig. 6. Geometry for loading by a skier with finite-width ski (w).

\section{SIMPLE ANALYSIS WITH IMPERFECTION IN A WEAK LAYER}

With an imperfection present in a weak layer, application of a load will result in amplification of stress and deformation conditions in the stress and strain concentrations associated with the imperfections analogous to the stress-intensity factor of fracture mechanics: the stress intensity at the tip of the imperfection is proportional to the intensity of stress applied remotcly at the top of the snowpack. Rice (1968) gave an expression for the stress-intensity factor for slip band (or crack) of length $2 a$ loaded in shear uniformly at the top of a slab. If $\tau_{\infty}$ is a uniform shear stress applied at the top of the slab and $\tau_{0}$ is the friction stress (e.g. residual shear strength) along the imperfection, the stress-intensity factor for shear fracture (mode II) propagation is given by: $K_{I I}=\left(\tau_{\infty}-\tau_{0}\right)(\pi a)^{0.5}$. Such a solution, from small-scalc yiclding linear elastic fracture mechanics, is too simple for use in the problem here, but illustrates in principle how a remotely applied shear stress (at the slab surface) affects propagation of an imperfection; the stress-intensity factor is, then, a convenient measure of load applied to the crack (imperfection) tip region. For example, if a line-source solution is applicd, the implicd shear stress intensity added at the top of the slab to $\tau_{\infty}$ may be approximated as $(P g \sin \Psi) / w$ where $w$ is the width of a ski. If $w=0.1 \mathrm{~m}, P=41.2 \mathrm{~kg} \mathrm{~m}^{-1}$ and $\Psi=35^{\circ}, \tau_{\infty}$ has the approximate valuc $2.3 \mathrm{kPa}$ which represents an increase in "intensity" applied to a weak zone from the skier-loading remotely applied shear stress at the top of the slab; its value is more than ten times the values calculated from skier loading by Equations (10) and (11) at depths exceeding $1 \mathrm{~m}$.

Rice (1968) emphasizes that such an analysis (linear elastic) does not take into account the response of the material to the applied load but it does illustrate the stressconcentrating effect once imperfections are introduced. The stress and deformation state induced by skier loading is not uniform as required by $K_{\text {II given above (such would bc }}$ approximately the case for new snowfall loading). Furthermore, the driving energy for propagation of an imperfection from fracture mechanics is proportional to the stress-intensity factor squared, and inversely proportional to the modulus $E^{\prime}=2 G /(1-\nu)$ where $G$ is shear modulus and $\nu$ is Poisson ratio of the slab. Rice (1973) and Bažant and Planas (1998) show that for the assumption of linear viscoclasticity in the slab and small-scale yielding in the weak layer, the reciprocal of modulus may be replaced by the time-dependent comnliance which contains the simnificant teinipuatiou dependence of alpine snow (McClung, 1996). This simple analysis shows how one is implicitly forced toward consideration of slab mechanical properties once imperfections are introduced.

Virtually all modern work on the snow slab (McClung, 1979, 1981, 1987; Conway and Abrahamson, 1988; Bader and Salm, 1990; Conway, 1998) postulates that the size effects controlling avalanche release are macroscopic, with a size effect independent of statistical properties in agreement with the arguments of Bažant and Planas. The size effects associated with sample-size dependence as in the (brittle) shcar frame test are microscopic and dependent on statistical properties. Microscopic flaws are present in abundance everywhere in alpine snow and there is evidence that such flaws are important for interpreting shear frame results. However, it is unlikely that such small flaws control avalanche release. If such small defects truly controlled avalanche release, avalanches would be present continuously. Howcver, experience shows that avalanches are actually rare occurrences. In fact, the strength of snow would be virtually zero if micro-scale flaws controlled (see J. F. Nye in IAHS, 1975). In the light of new experimental information 
on shear strength by Schweizer (1998) and information summarized by Bažant and Planas (1998) it is imperative to revisit the question of size effects, which we do in the next section.

\section{TWO ESTIMATES OF IMPERFECTION SIZE EFFECTS}

\section{(1) Simple brittle size effect from scaling}

If alpine snow behaved as a classical brittle material as might occur under rapid loading such as for explosives), a simple method to estimate order-of-magnitude size effects could be as discussed by Bader and Salm (1990). For a completely brittle matcrial, the ratio of fracture strength to theoretical ultimate (uncracked) strength is given by $\sigma_{f} / \sigma_{\mathrm{th}} \approx(b / a)^{1 / 2}$ (e.g. Kanninen and Popelar, 1985) where $b$ is atomic bond size and $a$ is critical crack length. Bader and Salm (1990) pointed out that for brittle materials such as glass, typical atom bond sizes are $2-5 \times 10^{-7} \mathrm{~mm}$ associated with minimum critical lengths of order $10^{-3} \mathrm{~mm}$ (Lardner, 1974). For snow grains, typical bond sizes are on the order of $0.1-1 \mathrm{~mm}$. Simple proportions yicld critical size effects of $0.2-5 \mathrm{~m}$ for snow. From Griffith's experiments on glass (Kanninen and Popelar, 1985) the ratio $\sigma_{\mathrm{f}} / \sigma_{\mathrm{th}}$ is $1 / 64$ using the bulk strength of glass (large samples) for $\sigma_{f}$, which (with $b=0.1-1 \mathrm{~mm}$ for snow) gives critical-size estimates $0.4-4 \mathrm{~m}$. The strength ratio for glass is of the same order as the ratio of typical avalanche failure strengths (about $1 \mathrm{kPa}$ : McClung and Schaerer, 1993, p.71; Jamieson and Johnston, 1998b) to the yield stress of single ice crystals in shear (about $100 \mathrm{kPa}$ : Higashi and others, 1964; Fletcher, 1970; Hobbs, 1974) which approximates the fracture stress (Lardner, 1974). This analysis is very crude but it is a starting-point for cstimating sizc cffects. The implication is that imperfections much smaller than the order-of-magnitude range $0.1-1 \mathrm{~m}$ would not be energetically favourable for reaching a selfpropagation condition.

\section{(2) Estimate of size effects for constant gravita- tional loads}

Snow cannot be approximated as a brittle material unless it is deformed very rapidly. The other limit, when snow displays strain-softening under constant load, was addressed by Palmer and Rice (1973). 'They gave a formalism to enable calculation of the size of the end zone (or plastic zonc) at the end of a slip surface generated by strain-softening initiated at an imperfection in a weak laycr with the slab assumed to be elastic. The estimate of the cohesive (or end) zone size, $\omega$, in terms of peak shear stress, $\tau_{p}$, residual shear stress, $\tau_{\mathrm{r}}$, shear modulus, $G$, Poisson ratio, $\nu$, and average shear displacement, $\delta$, in the strain-softening regime from a simple shear experiment is:

$$
\omega=\frac{9 \pi G \delta}{16(1-\nu) \tau_{\mathrm{p}}\left(1-\tau_{\mathrm{r}} / \tau_{\mathrm{p}}\right)} .
$$

Bažant and Planas (1998) provide an analogous expression for strain-softening materials in tension, and point out that the non-linear end-zone size may be many times the estimates for metals as estimated by Irwin (1958).

From our simple shear experiments (data from Schweizer, 1998, and unpublishcd collection of more than 200 experiments by McClung) the ratio of peak to residual shcar stress can be taken as 1.5 . The $G / \tau_{\mathrm{p}}$ ratio increases as the temperature decreases, due to the temperature dependence of $G$, and increases with strain rate, again possibly due to the dominance of stiffness. The ratio is about 100 for slow rates $\left(10^{-1} \mathrm{~s}^{-1}\right)$, increasing to 300 for higher rates $\left(10^{3} \mathrm{~s}\right)$. The average values of displacement in the strain-softening portion of the stress-strain curve range from $5 \mathrm{~mm}$ (slow rates) to $1 \mathrm{~mm}$ (fast rates). From these estimates the end-zonc size is estimated to be about $1.5 \mathrm{~m}$ (fast rates) to $3 \mathrm{~m}$ (slow rates) in field situations from Equation (12). Since the critical length must be a multiple of the end-zonc sizc, our estimate is somewhat higher than the one above based on scaling from bond sizes for brittle materials.

For reference, Bažant and Planas (1998) estimate for concrete in tension a fully developed fracture-process-zone size range of $0.3-2 \mathrm{~m}$ for large concrete structurcs. Our two cstimates have a certain consistency with respect to rate: smaller sizes are implied for more rapid loading and this is consistent with results for concrete described by Bažant and Planas (1998). These two limit estimates (brittle and strain-softening) are reasonably consistent and our best estimate for the important minimum critical-size effect for skier triggering is on the order of a significant fraction of a meter.

For skier triggering, once sizc cffccts for imperfections approach a significant fraction of a meter, the situation sccms to be critical as the extra dynamic loading will fced deformation energy to the tip to cause extension and catastrophic fracturc propagation. Furthermore, if a critical condition is not achieved by the first skier, passage of subsequent skiers can cause extension to a critical length. This explains some rare field observations (c.g. LaChapelle, 1985) in which an avalanche releases after the passage of more than one skier. Our static analysis without imperfections implies that the applied loads arc vcry small at depth, whereas field data (Schweizer and others, 1995a, b; see Appendix) show that dynamic loads are higher. The application of dynamic loads and the presence of partially formed (subcritical) imperfections to concentrate deformation provide a powerful combination to drive propagating shcar fractures from imperfections which are subcritical before passage.

Our size-effect estimate is a significant fraction of a ski length, and from St Venant's principle the slope distance for the zone of influence of significant stresses and deformation energy by passage of a skier will be a few ski lengths. If small (micro-scale) imperfections were responsible for avalanche release, a person on skis would influence huge numbers of them in skiing down a given slope, and skicr triggering would be far more common than it is. Skiers sometimes term positions on snow slopes where avalanches initiate as "sweet spots". We belicve "sweet spots" are preferentially located where subcritical imperfections coincide with thin- and/or soft-snow slabs so that maximum deformation energy is communicated to the weak layer during skier passage.

Most snow-slab releases (either natural or human-triggered) occur under loading conditions. In fact, avalanche releases under constant gravitational loads (e.g. rcleases after storms without wind loading) are very rare in comparison, probably because bond formation may inhibit imperfection expansion if growth is too slow. Therefore, wc believe subcritical imperfections and their growth under loading are of primary importance in the vast majority of cases. Furthermore, there is no requirement for a strain-softening process to have occurred in a weak layer over large 
distances (many meters) as envisioned by Conway and Abrahamson (1988) to place the slab weak-layer system in a critical condition with respect to future load application. Bader and Salm (1990) hypothesized that critical lengths for imperfections to start propagation are on the order of scveral meters, with brittlc fracture starting at distances of tens of meters, but they did not consider the problem of skier triggering explicitly. Observations concerned with fracture propagation during skiing show that Badcr and Salm's distances $(1060 \mathrm{~m})$ are unrealistic for skier triggering: shear fractures propagate rapidly within a few meters of initiation, implying very high stresses and deformation rates.

Once the minimum conditions for imperfection growth are approached, further load application can result in shear fracture (Bažant and Planas, 1998) essentially at peak stress if loading is progrcssive (load-controlled), as may be approximated by new snowfall loading (McClung, 1981) with no requirement for strain-softening. Bažant and Planas (1998) show that instability may result from further application of load at any time after a peak has been reached for strain-softening material in the failure zone (weak layer), given that the critical fracture energy has been delivered and the size requircment is satisfied.

The fact that strain-softening is not required for fracture initiation under loading, along with our estimates of size effects, again points to critical imperfection size effects of a fraction of a meter for dynamic loading applied during skiing. 'The presence of an imperfection will concentrate stresses, deformation and deformation rates to help achievc a critical condition, with thin, soft slab material being of primary importance to deliver maximum deformation energy to the weak layer.

\section{SUMMARY}

'The immediate or nearly immediate effects of snow temperatures on snow-slab instability are influences which promote instability under warming, including reduced snow stiffness (or hardness), and strength with very short time delays to affect properties; failure loughness increases slightly with incrcasing temperature. However, we expect overall fracture toughness for snow-slab stability to decrease with increasing temperature since weak-layer failure toughness appears weakly temperature-dependent, while the slab stiffness should decrease with increasing temperature. Other temperature effects include metamorphism and long-term creep and they can affect skier triggering, but such effects are beyond the scope of this paper.

In order to include the effects of snow temperature in an analysis of instability, one must seek out information about slab hardness and think about the problem in regard to deformation energy rather than an analysis of stresses. Conventional stability evaluation (e.g. calculation of a strength-to-load ratio) will not contain much of the important information about slab-temperature dependence (or snow hardness) and instability.

For skier triggering, the most important immediate influcnce of snow temperatures is the decrease of hardness of the surface layers under warming. Secondary effects include decreased shear strength if the weak layer is warmed, with failure toughness being (apparently) only slightly temperature-dependent. Hardness estimates (e.g. the hand hardness test) implicitly include snowtemperature effects.

Mathematically, our static stress analysis indicates that new snow loading or skier loading should always decrease stability if snow is modelled as a linear Coulomb-Mohr material (the usual assumption, which wo belicve is unrealistic). However, when results from shear frame cstimates of the stability index are combined with measured peak friction angles from simple shear tests for alpine snow, this mathematical condition may not always be fulfilled: it might be implied that stability increases with loading. We believe the discrepancy may be found in the imprecision of shear frame measurements combined with extrapolation of such results to the real situation where macroscopic imperfections will control avalanche initiation. Neither simple shcar tests nor the shear frame will include the effects of macroscopic imperfections. Simple shear tests should provide peak friction angles closer to values for a homogeneous Coulomb-Mohr material compatible with the analysis leading to Expressions (5) and (9). The stress concentrations induced by the fins of the shcar frame might produce artificially lower friction angles, but these should not be cquated with the field situation in which macroscopic imperfections, perhaps larger in size than the shear frame, can initiate the failure process.

'The Rutschblock test has the advantage that it implicitly includes dynamic cffects, snow temperatures and slab hardness effects in an analysis of instability, whereas tests like the shovel shear test or the shear frame test do not. The drawback is that another source of variation is included that must be considered for extrapolation: the test results depend heavily on the surface layer stiffness. It is proposed to perform Rutschblock tests at places with relatively soft rather than hard surface layers for comparison and extrapolation. Furthermorc, tests will have a better chance of revealing instability where the slab is thin.

The advantage of the shovel test and shear frame test is that they contain dircet information about the strength and quality of wcak-layer failures, and thercfore thcir interpretation is less complicated than the Rutschblock test. However, they do not contain the most important information about snow tempcratures and hardness, and therefore supplementary information about the slab properties must be sought. This same comment applies to the calculated shear frame index. We propose that to complete a stability test, observations of hardness variations be madc (c.g. with a profile), otherwisc the information gained by the tests is too limited and cannot easily be used for cxtrapolation.

Field observations show that most skier-triggered avalanches occur during the act of skiing, which implies $\mathrm{dy}$ namic loading in which stresses and deformation will be higher than for a static analysis. Dynamic deformation measurements (Fig. 7; Schweizer and others, 1995a, b) compared with a static analysis show that a realistic treatment of the problem would require dynamic effects to be included.

Any information that helps to evaluate snow-slab instability is useful, and this includes calculation of the sta- 


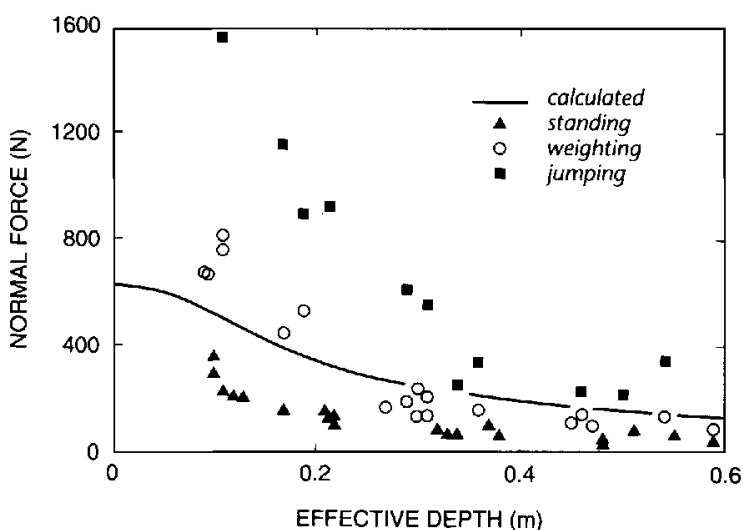

Fig. 7. Calculated force for a skier standing with $0.2 \mathrm{~m}$ combined width of skis (solid line) compared with static and dynamic measurements (Camponozo and Schweizer, 1996). Dynamic stresses during skiing would be closest to the data for jumping.

bility index from, for example, the shear frame and the other common stability tests. In this paper, we have addressed the problem of skier triggering in an attempt to place it in its true context: a forecasting problem on the micro-scale for terrain (the scale involving individual terrain features) in which a general stability index is only a good first step. Consideration should also be given to slab mechanical properties, the size effects associated with fracture propagation, and influences of terrain as primary factors for avalanche forecasting on individual terrain features. McClung and Schaerer (1993) argued that stability tests constitute some of the most important information available for back-country avalanche forecasting. However, in this paper we provide analysis to show that some kcy information is often excluded by stability tests and that some of the key information such as location of subcritical imperfections can be virtually impossible to gauge. What we have donc, then, is to indicate that the snow-stability cvaluation problem is analogous to a probabilistic risk analysis in which the risk (uncertainty) is never zero. The fundamental problem in back-country avalanche forecasting is a knowledge of the temporal and spatial distribution of snow instability which cannot be known exactly. Risk management, then, becomes another term for back-country travel in avalanche terrain.

\section{ACKNOWLEDGEMENTS}

The support of the Natural Sciences and Engineering Rescarch Council of Canada is gratefully acknowledged. This work was also supported by the Peter Wall Institute of Advanced Studies, Lniversity of British Columbia. The support of our industrial research partner, Canadian Mountain Holidays, has been essential to this work. Our simple shear experiments were performed at Glacier National Park, British Columbia. We are grateful to the Canadian Parks Service for thcir support.

\section{REFERENCES}

Bader, H. P, and B. Salm. 1990. On the mechanics of snow slab release. Cold Reg. Sci. Technol, 17(3), 287-300.

Bažant, Z. P. and J. Planas. 1998. Fracture and size effect in concrete and other quasibrittle materials. Boca Raton, FL, CRC Press.

Bjerrum, L. 1967. Progressive failure in slopes of oversonsolidated plastic clay and clay shales. Trans. Am. Soc. Cizil Engineers SM93, 3-49.

Broek, D. 1986. Elementary engineering fracture mechanics. Fourth edition. Dordrecht, Kluwer.

Camponovo, C. and J. Schweizer. 1997. Measurements on skier triggering. In ISSW'96. International Snow Science Workshof, ti-10 October 1996, Banff, Alberta. Proceedings. Revelstoke, B.C., Canadian Avalanche Association $100)-103$.

Conway, H. 1998. The impact of surface perturbations on snow-slope stability. Ann. Glaciol, 26, 307-312.

Conway, H. and J. Abrahamson. 1988. Snow-slope stability-- a probabilistic approach. f. Glaciol, 34(117), 170-177.

Das, B. M. 1983. Advanced soil mechanics. New York, McGraw-Hill Book Company.

Fletcher, N. H. 1970. The chemical physics of ice. Cambridge, Cambridge Lniversity Press.

Föhn, P. M. B. 1987. The stability index and various triggering mechanisms, International Association of Hydrological Sciences Publication 162 Symposium at Davos 1986 - Avalanche Formation, Mavement and Effects i, 195-214.

Fohn, P. M. B. 1989. Snowcover stability tests and the areal variability of snow strength. In A merging of theory and practice. Proceedings of the International Snow Srience Workshop, 12-15 October 1988, Whistler, B.C. Vancouver, B. C., Canadian Avalanche Association, 262-273.

Freudenthal, $\Lambda$. M. 1968. Statistical approach to brittle fracture. In Liebowitz, H., ed. Fracture: an advanced treatise. Vol. II. New York, Acactemic Press, $591-619$.

Higashi, A., S. Koinuma and S. Mae. 1964. Plastic yielding in ice single crystals. Jpn. J. Appl. Phys., 3(10), 610) 616.

Hobbs, P. V. 1974. Ice physies. Oxford, Clarendon Press.

International Association of Hydrological Sciences (IAHS). 1975. General discussion. International Association of Hydrological Sciences Publication 114 (Symposium at Grindelwald 1974 Snow Mechanics), 441-442.

Irwin, G. R. 1958. Fracture. In Flügge, ed. IIandbuch der Physik. Berlin, Springer-Verlag, 551-590.

Jamieson, J. B. 1995. Avalanche prediction for persistent snow slabs. (Ph.I. thesis, University of Calgary:

Jamieson, J. B. and T. Geldsetzer. 1996. Azalanche accidents in Canada. Vol. 4. 1984-1996. Revelstokc, B.C., Canadian Avalanche Association.

Jamieson, J. B. and C. D. Johnston. 1995. Interpreting rutschblocks in avalanche start zones. Avalanche Vews 46, 2-4.

Jamicson, J. B. and C. D. Johnston. 1998a. Refinements to the stability index for skier-triggered dry-slab avalanches. Ann. Glaciol, 26, 296302

Jamieson, J. B. and C. D. Johnston. 1998b. Snowpack characteristics for skier triggering. Avalanche News $55,3139$.

Kanninen, M. F. and C. H. Popelar. 1985. Advanced fracture mechanics. Oxford, etc., Oxford University Press.

LaChapelle, E. R. 1985. The ABC f avalanche safety. Secondedition. Seatule, WA The Mountaincers.

Lardner, R.W. 1974. Mathematical theory of dislocations and fracture. 'loronto Ont., University of Toronto Press.

McClung, D. M. 1977. Direct simple shear tests on snow and their relation to slab avalanche formation. F. Glaciol., 19 (81), $101-109$.

McClung, D. M. 1979. Shear fracture precipitated by strain softening as a mechanism of dry slab avalanche release. 7. Geophys. Res., 84 (B7), 35193526.

McClung, D. M. 1981. Fracture mechanical model of dry slab avalanche release. 7. Geophys. Res, 86 Blli, 10,783 10,790

Mc Clung, D. M. 1987. Mechanics of snow slab failure from a geotechnical perspective. International Association of Hydrological Sciences Publication 16 (Symposium at Davos 1986 - Avalanche Formation, Movement and Effects) $475-508$.

McClung, D. M. 1995. The effects of temperature on fracture of dry Alpine snow. In Sivardière, F., ed. Les apports de la recherche scientifique à la sécurite neige, glace et avalanche. Actes de Colloque, Chamonix 30 mai-3 juin 1995 Grenoble, Association Nationale pour l'Étude de la Neige et des Avalanches (ANENA), 317-322.

McClung, 1). M. 1996. Elfects of temperature on fracture in dry slab avalanche release. f. Geophys. Res., 101 (B10), 21,907-21,920.

McClung, D. M. and P.A. Schaerer. 1993. The avalanche handbook. Seatte, WA, The Mountaineers.

Palmer, A. C. and J. R. Rice. 1973. The growth of slip surfaces in the progressive failure of over-consolidated clay. Proc. R. Sac. London, Ser. A, 332 [59]) $527-548$.

Perla, R. 1977. Slab avalanche measurements. Can. Geutech. 7., 14(2), 206-213.

Perla, R. 1980. Avalanche release, motion, and impact. In Colbeck, S., ed. Dynamics of snow and ire masses. New York, Academic Press, 397-462.

Pisarenko, G. S. ed. 1969. High-temperature strength of materials. Kiev, Academy of Sciences of the Ukrainian SSR. Institute for Problems of Materials; Jerusalem. Israel Program for Scientific Translations. 
Rice, J. R. 1968. Mathematical analysis in the mechanics of fracture. In Liebowitz, H., ed. Fracture: an adtanced tratise. Wol. II. New York, Academic Press, 191-311.

Rice, J. R. 1973. The initiation and growth of shear bands. In Palmer, A. C. ed. Symposium on the Role of Plasticity in Soul Mechanics, 13-15 September, 1973, Cambridge. Proceedings. Cambridge, Lnivesity of Cambridge Engineering Department, 263-278.

Roch, A. 1966. Les déclenchements davalanches. International Association of Srientific Hydrology Publication 69 (Symposium at Davos 1965 - Scientific Aspects of Snow and Ice Avalanches), 182-195.

Schweizer, J. 1998. Laboratory experiments on shear failure of snow. Ann. Glaciol., 26, 97-102.

Srhwrizer, J., C. Camponovo, C. Fieř and P. M. B. Föhn. 1995a. Skicr triggered slab avalanche release - some practical implications. In Sivardière, F., ed. Les apports de la recherche scientifique à la sécurité neige, glace et avalanche. Actes de Colloque, Chamonix 30 mai-3 juin 1995. Grenoble, Association Nationale pour l'Étude de la Neige et des Avalanches (ANENA) 309-315.

Schwcizer, J., M. Schnecheli, C. Ficrz and P. M. B. Föhn. 1995b. Snow mechanics and avalanche formation: field experiments on the dynamic response of the snow cover. Surv Geophys. 16(5-6,621 633.

Sommerfeld, R. A. 1980. Statistical models of snow strength. 7. Glaciol., $2694,217-223$.

I"imoshenko, S. P. and J. N. Goodier. 1970. Theory of elasticity. Third edition. New York, etc., McGraw-Hill.

\section{APPENDIX}

\section{STATIC ANALYSIS FOR A SKI OF FINITE WIDTH}

In this $A$ ppendix, we relate the analysis accompanying Figures 4 and 5 in the text with the loading and geometry depicted in Figure 6. Pure shear loading is applied in the $y$ direction of magnitude $2 B \pi$, and compressive loading is applied with magnitude $2 A \pi$ in the $x$ direction. Our analysis is a slight extension of that given by Timoshenko and Goodier (1970), so the solution methods we present are well known in engincering mcchanics. The stress intensity in shear is $q_{\mathrm{s}}=2 B \pi=P g \sin \Psi / w$ and in the normal direction is $q_{n}=-2 A \pi=P g \cos \Psi / w$ wherc $P$ is the skier mass divided by the ski length $\left(\mathrm{kg} \mathrm{m}^{-1}\right)$ and $w$ is the ski width.

The stresses in the problem are then defincd by the standard equations of elasticity in polar coordinates. From Das (1983) and Föhn (1987), it can be shown that:

$$
\begin{aligned}
\Delta \tau_{x y}= & 2 B\left(\sin \theta \cos \theta-\sin \theta_{1} \cos \theta_{1}\right)-2 B\left(\theta-\theta_{1}\right) \\
& -A\left[\left(\cos ^{2} \theta-\sin ^{2} \theta\right)-\left(\cos ^{2} \theta_{1}-\sin ^{2} \theta_{1}\right)\right] .
\end{aligned}
$$

The engineering shear strain is then:

$$
\Delta \gamma_{x y}=\frac{\Delta \tau_{x y}}{G}
$$

so that hardness and temperature dependence is introduced through $G$. In Equation (Al), $\theta_{1}$ is defined by $\tan \theta_{1}=$ $(H \tan \theta+w) / H$ at any depth $H$.

For the calculations in Figure 6, we chose the same parameters as in Figures 4 and $5\left(\Psi=35^{\circ}, P=41.2 \mathrm{~kg} \mathrm{~m}\right.$, $\theta=35^{\circ}$ ) and the width of the ski $w=0.1 \mathrm{~m}$. For the slab density in Figure 7 we took $\rho_{\mathrm{s}}=200 \mathrm{~kg} \mathrm{~m}^{-3}$. The calculations again show that stresses and strains decrease inverscly proportional to $H$ and the stress ratio: $\Delta \tau / \tau$ is then inverscly proportional to $H^{2}$. Since the calculations depend on ski width and the value of $\theta$, the results for finite ski width (Figs 4 and 5) are somewhat different than those for infini- tesimal ski width. The stresses implicd by any of these calculations for typical large slab depths are extremely small. The results indicate that dynamic effects coupled with imperfections and anisotropic deformations in weak layers appear to be important elements of the skier-triggering problem.

In order to compare with ski deformation experiments, we set $\Psi=0^{\circ}$, then $B=0$, to yield (Timoshenko and Goodier, 1970):

$$
\Delta \sigma_{\mathrm{r}}=\Delta \sigma_{\theta}=2 A\left(\theta-\theta_{1}\right)
$$

which represents a uniform compressive stress.

From Equation (A3) the displacements in plane strain below the ski are of the form:

$$
\begin{gathered}
u_{\mathrm{r}}=\frac{2 A}{E^{*}}\left(1-\nu^{*}\right) r \theta \\
v_{\theta}=-\frac{4 A}{E^{*}} r \ln r,
\end{gathered}
$$

with similar expressions following from Equation (Al) by replacing $A$ with $-A, r$ with $r_{1}$, and $\theta$ with $\theta_{1}$ in Equation (Al). In Equation (A4), $E^{*}=E /\left(1-\nu^{2}\right)$ and $\nu^{*}=$ $\nu /(1-\nu)$ with $E$ and $\nu$ being Young's modulus and Poisson's ratio, respectively. Figure 8 shows the downward deformation component (along the $y$ axis) in the vicinity of the centre of the ski (near the foot) where $-A=P g / 2 \pi w$ from the work of Timoshenko and Goodier (1970). Again, temperature and hardness enter through $E$ and $\nu$.

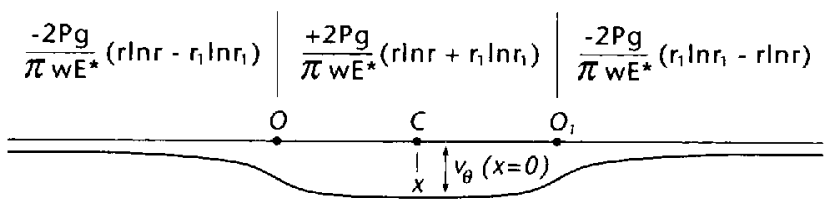

Fig. 8. Plane-strain deformation pattern for a skier with ski width wetween $O$ and $O_{1}$ (adapted from Timoshenko and Goodier, 1970).

At the midpoint below the ski, $\theta=-\theta_{1}$ and $r=r_{1}$ to yield the downward displacement:

$$
\begin{aligned}
u_{x}(y & =0) \\
& =\frac{4 P g}{\pi w E^{*}}\left(1-\nu^{*}\right) r_{1} \theta_{1} \cos \theta_{1}+\frac{4 P g}{\pi u E^{*}}\left(r_{1} \ln r_{1}\right) \sin \theta_{1}
\end{aligned}
$$

where $\theta_{1}=\tan ^{-1}(w / 2 H)$ and $r_{1}=\left[H^{2}+(w / 2)^{2}\right]^{0.5}$. Similarly, the vertical stress below the midpoint is:

$$
\Delta \sigma_{x}=\frac{2 P g}{\pi w}\left[\tan ^{-1}(w / 2 H)+\frac{2 w H}{w^{2}+4 H^{2}}\right] .
$$

Equations (A5) and (A6) may be used to compare with skier deformation measurements (Schweizer and others, 1995 a, b). Figure 7 shows this comparison for vertical stress calculated from Equation (A6) for a combined ski width of $0.2 \mathrm{~m}$ and $P g=500 \mathrm{~N} \mathrm{~m}^{-1}$. The loading plate has an area of $0.25 \mathrm{~m}^{2}$ for conversion of stresses to forces. Note that static loads are much lower than dynamic loads. Since the experimentally estimated forces on the plate are calculated from deformation measurements which are communicated through the snow, they depend on snow hardness which is not considered in the elastic analysis of Equation (A6). Therefore, the comparison of calculated forces from Equation (A6) in Figure 7 is an approximation. 